\title{
Canopy Size and Light Use Efficiency Explain Growth Differences between Lettuce and Mizuna in Vertical Farms
}

\author{
Theekshana C. Jayalath and Marc W. van Iersel *(D)
}

check for

updates

Citation: Jayalath, T.C.;

van Iersel, M.W. Canopy Size and

Light Use Efficiency Explain Growth

Differences between Lettuce and

Mizuna in Vertical Farms. Plants 2021,

10, 704. https://doi.org/10.3390/

plants10040704

Academic Editors: Rosario Muleo and Valeria Cavallaro

Received: 28 February 2021

Accepted: 2 April 2021

Published: 6 April 2021

Publisher's Note: MDPI stays neutral with regard to jurisdictional claims in published maps and institutional affiliations.

Copyright: (c) 2021 by the authors. Licensee MDPI, Basel, Switzerland. This article is an open access article distributed under the terms and conditions of the Creative Commons Attribution (CC BY) license (https:// creativecommons.org/licenses/by/ $4.0 /)$.
Department of Horticulture, University of Georgia, Athens, GA 30602, USA; tcjay@uga.edu

* Correspondence: mvanier@uga.edu; Tel.: +1-706-583-0284

\begin{abstract}
Vertical farming is increasingly popular due to high yields obtained from a small land area. However, the energy cost associated with lighting of vertical farms is high. To reduce this cost, more energy efficient (biomass/energy use) crops are required. To understand how efficiently crops use light energy to produce biomass, we determined the morphological and physiological differences between mizuna (Brassica rapa var. japonica) and lettuce (Lactuca sativa 'Green Salad Bowl'). To do so, we measured the projected canopy size (PCS, a morphological measure) of the plants throughout the growing cycle to determine the total amount of incident light the plants received. Total incident light was used together with the final dry weight to calculate the light use efficiency (LUE, g of dry weight/mol of incident light), a physiological measure. Plants were grown under six photosynthetic photon flux densities (PPFD), from 50 to $425 \mu \mathrm{mol} \mathrm{m}^{-2} \mathrm{~s}^{-1}$, for $16 \mathrm{~h} \mathrm{~d}^{-1}$. Mizuna and lettuce were harvested 27 and 28 days after seeding, respectively. Mizuna had greater dry weight than lettuce $(p<0.0001)$, especially at higher PPFDs (PPFD $\geq 125 \mu \mathrm{mol} \mathrm{m}{ }^{-2} \mathrm{~s}^{-1}$ ), partly because of differences in the projected canopy size (PCS). Mizuna had greater PCS than lettuce at PPFDs $\geq$ $125 \mu \mathrm{mol} \mathrm{m}{ }^{-2} \mathrm{~s}^{-1}$ and therefore, the total incident light over the growing period was also greater. Mizuna also had a higher LUE than lettuce at all six PPFDs. This difference in LUE was associated with higher chlorophyll content index and higher quantum yield of photosystem II in mizuna. The combined effects of these two factors resulted in higher photosynthetic rates in mizuna than in lettuce $(p=0.01)$. In conclusion, the faster growth of mizuna is the result of both a larger PCS and higher LUE compared to lettuce. Understanding the basic determinants of crop growth is important when screening for rapidly growing crops and increasing the efficiency of vertical farms.
\end{abstract}

Keywords: canopy size; incident light; light interception; light use efficiency; mizuna; projected canopy size; quantum yield of photosystem II

\section{Introduction}

Vertical farming refers to hydroponic crop production in buildings with precise environmental control. Vertical farms do not require arable land and can obtain high crop yields from a small land area. Therefore, vertical farms are becoming popular in urban areas. However, the energy costs associated with the required electric lighting and environmental control, especially cooling and dehumidification, in vertical farming are high [1]. The cost of electric lighting in controlled environment agriculture in just the United States has been estimated at $\sim \$ 600$ million annually [2]. To bring this cost down, research into more efficient production techniques [3] and more energy-efficient crops (more biomass gain per unit of energy use) are required.

Overall, crop growth is a function of the amount of incident light reaching the canopy, which depends on projected canopy size (PCS) [4,5], and light use efficiency (LUE, grams of biomass produced per mol of incident light) [6]. To screen for crops with rapid growth, quantifying PCS development and LUE is essential.

Plants that produce a larger canopy can achieve faster growth by increasing the amount of incident light reaching the canopy compared to plants with a smaller canopy $[4,5]$. 
As incident light increases, canopy photosynthesis and biomass accumulation of plants also increase [5], as long as canopy photosynthesis is not light-saturated. This in turn helps plants to produce additional canopy faster than plants with a smaller canopy [4]. Therefore, quantifying the PCS and determining how this affects the amount of incident light, is important. Non-destructive digital imaging has been used in many crops, including tomatoes [7], soybean [8], and lettuce [5,9]. Periodic PCS measurements can be used to estimate the daily PCS [6]. Combining those data with PPFD data allows for estimation of the total incident light over the course of the growing cycle. Projected canopy size is also valuable to make crop growth predictions, since PCS early in the growing cycle may be correlated with the final dry weight of the crop, as we have previously shown in lettuce (Lactuca sativa) [6,10] and black-eyed susan (Rudbeckia fulgida) [11].

The LUE of a crop describes how efficiently plants use the incident light for growth. The LUE can be calculated by dividing the dry weight of a plant by the total incident light that the plant received throughout the growing period [6]. This provides a physiological measure of how efficiently crops use light, in contrast to calculating LUE based on the amount of light provided to the growing space, which provides insight into production efficiency, but not underlying physiological mechanisms [6]. Factors such as chlorophyll content, the quantum yield of photosystem II ( $\Phi_{\mathrm{PSII}}$, the fraction of absorbed photons used to drive photochemistry), and $\mathrm{CO}_{2}$ assimilation are all important in determining the LUE of a crop.

Higher chlorophyll content increases light absorption [12]. The energy of the absorbed photons can then be used in the light reactions of photosynthesis to drive photochemistry (electron transport), while some light energy is dissipated as heat (NPQ, non-photochemical quenching), or re-emitted as fluorescence. Photochemistry competes with NPQ and chlorophyll fluorescence for excitation energy from photons $[13,14]$. To understand how different lighting strategies affect plant growth, it is important to determine $\Phi_{\text {PSII }}$, since this partly determines how efficiently plants use the absorbed light to drive photosynthesis and produce biomass. Previous studies have shown that increasing PPFD decreases $\Phi_{\text {PSII }}$, due to the partial closing of photosystem II reaction centers and upregulation of NPQ [15,16]. Although $\Phi_{\text {PSII }}$ decreases, the electron transport rate (ETR) increases with increasing PPFD [15-17]. The $\Phi_{\text {PSII }}$ of different species responds differently to increasing PPFDs [16]. In addition, plants acclimated to high light have higher $\Phi_{\text {PSII }}$ and ETR than those acclimated to low light. Therefore, to increase the production efficiency in plant factories, identifying crops with both high $\Phi_{\text {PSII }}$ and high ETR is important, because a higher ETR will result in the production of more ATP and NADPH for use in $\mathrm{CO}_{2}$ assimilation. Both high $\Phi_{\text {PSII }}$ and high chlorophyll content index (CCI) may increase the ETR, $\mathrm{CO}_{2}$ assimilation rate, and potentially the growth rate of plants.

A previous indoor study with mizuna (Brassica rapa var. japonica) and oakleaf lettuce (Lactuca sativa 'Green Salad Bowl') found much faster growth of mizuna compared to lettuce [18]. This growth difference must be the result of morphological and/or physiological differences between the two crops, but those underlying reasons were not explored in that study. A better understanding of the underlying reasons for growth differences among crops will facilitate screening for rapid-growing crops and cultivars that are well-suited for vertical farming production systems. It can also enable breeding efforts by providing selection criteria for crops that are well-suited for production in vertical farms. Therefore, our objective was to determine the underlying mechanisms for the growth differences between mizuna and lettuce. We hypothesize that the faster growth of mizuna is the result of a greater PCS, increased canopy incident light, and higher LUE. Since crop growth is affected by PPFD, we also determined how different PPFDs affect the morphological and physiological factors underlying crop growth. Comparing two species, grown at different PPFDs, allowed us to determine how useful PCS and LUE are in explaining crop growth. 


\section{Results}

\subsection{Experiment}

To determine the underlying morphological and/or physiological reasons for growth differences between mizuna and lettuce at different PPFDs, plants were grown at six PPFD levels ( 50, 125, 200, 275, 350, and $425 \mu \mathrm{mol} \mathrm{m}^{-2} \mathrm{~s}^{-1}$ at the center of each section) for a 16-hr photoperiod. Projected canopy size was measured twice a week throughout the growing period, and those images were used to estimate the daily PCS and to calculate the total incident light per plant over the growing period. In addition, leaf chlorophyll content index (CCI), anthocyanin content index (ACI), $\Phi_{\mathrm{PSII}}$, and net $\mathrm{CO}_{2}$ assimilation of both crops were measured during the study. Mizuna and lettuce were harvested 27 and 28 days after seeding, respectively. The total leaf area and shoot dry weight were measured. Finally, the LUE was calculated by dividing shoot dry weight by the total incident light over the growing period.

\subsection{Projected Canopy Size}

Projected canopy size of both crops increased sigmoidally over time. A PPFD of $50 \mu \mathrm{mol} \mathrm{m}{ }^{-2} \mathrm{~s}^{-1}$ resulted in a much lower PCS of both crops compared to PPFD levels $\geq 125 \mu \mathrm{mol} \mathrm{m} \mathrm{m}^{-2} \mathrm{~s}^{-1}$. The PCS of mizuna at the end of the growing cycle was $\sim 340 \mathrm{~cm}^{2} /$ plant at PPFDs $\geq 200 \mu \mathrm{mol} \mathrm{m}{ }^{-2} \mathrm{~s}^{-1}$ (Figures 1 and 2). For lettuce, PCS was similar ( $240 \mathrm{~cm}^{2} /$ plant) at all PPFDs $\geq 125 \mu \mathrm{mol} \mathrm{m}^{-2} \mathrm{~s}^{-1}$ (Figures 1 and 2). Mizuna had a larger PCS than lettuce starting from the early growth stages at PPFDs $>50 \mu \mathrm{mol} \mathrm{m}{ }^{-2} \mathrm{~s}^{-1}$ (Figure 1). The difference in PCS between the two species increased over time, especially at higher PPFDs $\left(\geq 200 \mu \mathrm{mol} \mathrm{m}^{-2} \mathrm{~s}^{-1}\right.$ ) (Figure 1).

The PCS of both crops at harvest was low at a PPFD of $50 \mu \mathrm{mol} \mathrm{m}^{-2} \mathrm{~s}^{-1}$ and increased asymptotically with increasing PPFD $(p<0.0001$, Figure 2$)$. The PCS of both crops was similar at PPFDs of 50 and $125 \mu \mathrm{mol} \mathrm{m} \mathrm{m}^{-2} \mathrm{~s}^{-1}$. However, the PCS of lettuce did not increase further at PPFDs $\geq 125 \mu \mathrm{mol} \mathrm{m}^{-2} \mathrm{~s}^{-1}$, while mizuna PCS was similar at PPFDs $\geq 200 \mu \mathrm{mol} \mathrm{m}{ }^{-2} \mathrm{~s}^{-1}$. At PPFDs $\geq 200 \mu \mathrm{mol} \mathrm{m}^{-2} \mathrm{~s}^{-1}$, mizuna had a greater PCS than lettuce (Figure 2).

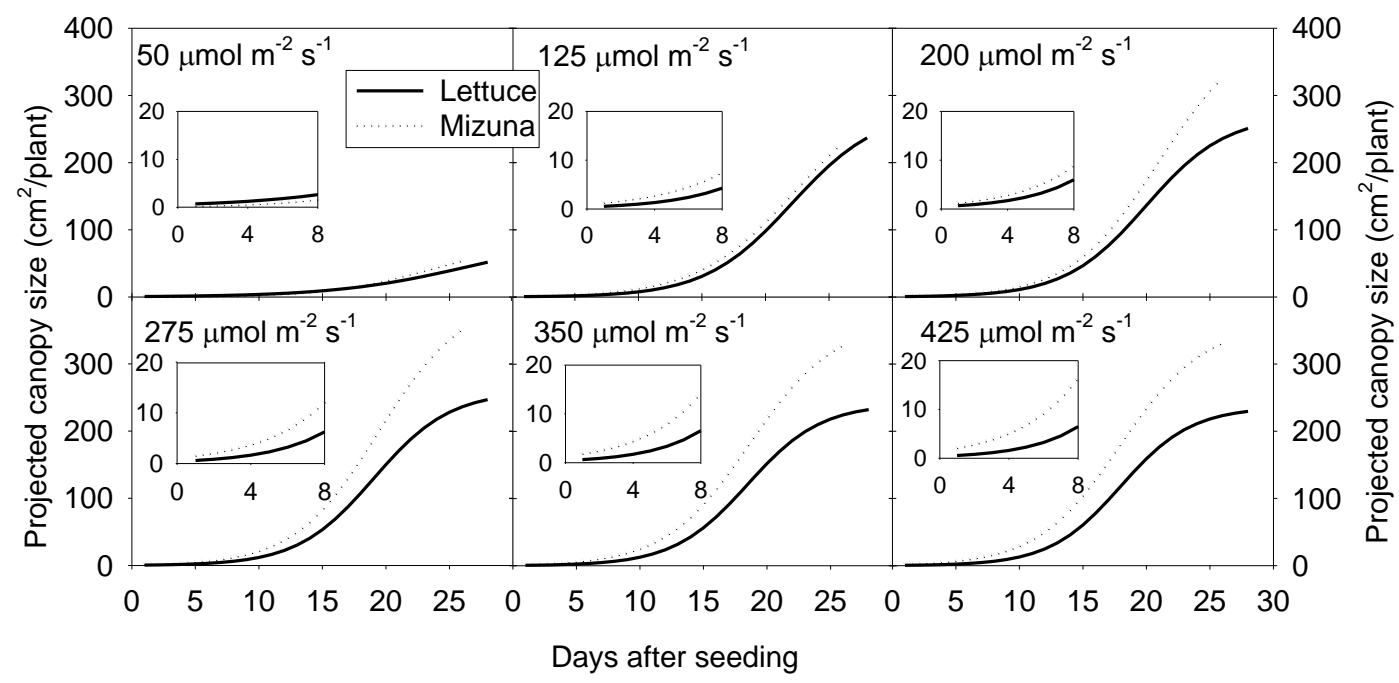

Figure 1. Sigmoidal regression curves fitted through the projected canopy size (PCS) data of mizuna (Brassica rapa var. japonica) and lettuce (Lactuca sativa 'Green Salad Bowl') over the course of the growing cycle for plants grown at six different photosynthetic photon flux densities (PPFD, upper left corner of each graph) ( $R^{2} \geq 0.99$ for all curves). Inserts show the PCS during the first eight days of the study. 


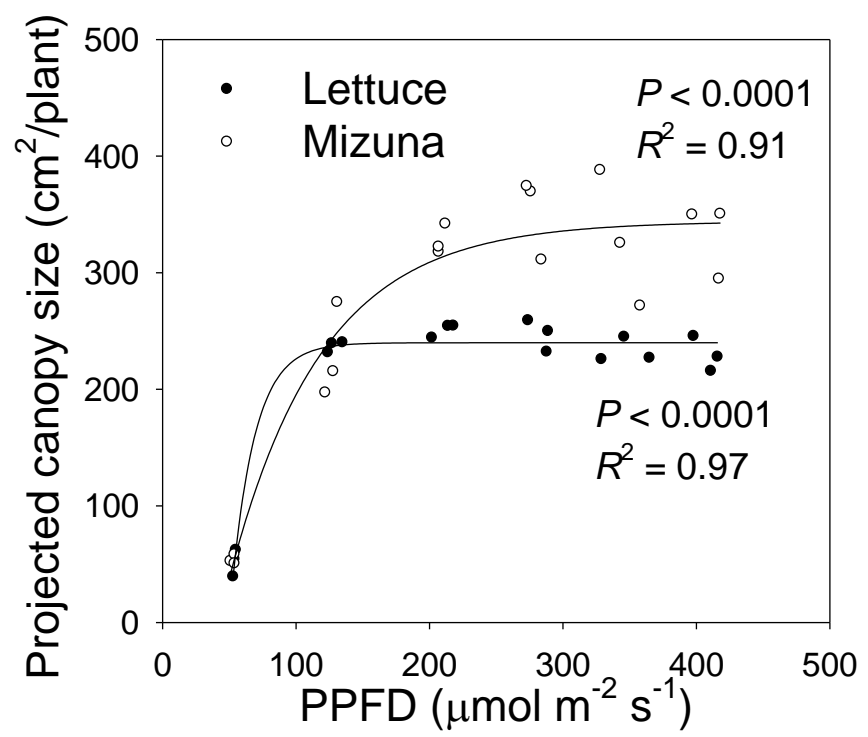

Figure 2. The projected canopy size (PCS) of mizuna (Brassica rapa var. japonica) and lettuce (Lactuca sativa 'Green Salad Bowl') plants grown at six different photosynthetic photon flux densities (PPFDs). Data were collected at the end of the growing cycle (27 and 28 days for mizuna and lettuce, respectively). Each data point represents the mean of nine plants.

\subsection{Incident Light}

The incident light integrated over the entire crop cycle increased with higher PPFD levels for both crops, but this increase was more pronounced for mizuna than for lettuce (Figure $3, p<0.0001$ ).

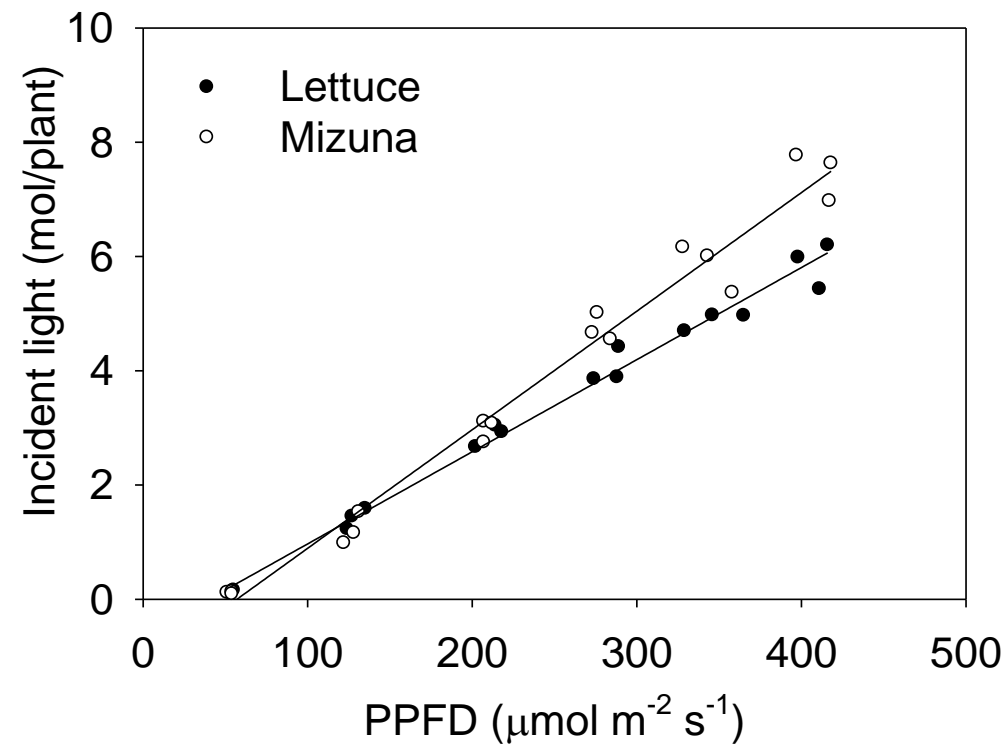

Figure 3. The total incident light on the plant canopy throughout the growing period of mizuna (Brassica rapa var. japonica) and lettuce (Lactuca sativa 'Green Salad Bowl') plants grown at six different photosynthetic photon flux densities (PPFDs) for 27 and 28 days, respectively. Lines show the results from multiple regression analysis $\left(R^{2}=0.98\right)$, which indicated a significant species $\times$ PPFD interaction $(p<0.0001)$. Each data point represents the mean of nine plants.

\subsection{Chlorophyll Content Index and Anthocyanin Content Index}

Increasing the PPFD increased both CCI and anthocyanin content index (ACI) of both crops $(p \leq 0.003)$ (Figure 4). This was more pronounced in mizuna than in lettuce; CCI of 
mizuna increased by 0.08 for each $\mu \mathrm{mol} \mathrm{m}{ }^{-2} \mathrm{~s}^{-1}$ increase in PPFD, compared to an increase of 0.01 per $\mu \mathrm{mol} \mathrm{m}{ }^{-2} \mathrm{~s}^{-1}$ in lettuce. As the PPFD increased from 50 to $400 \mu \mathrm{mol} \mathrm{m}^{-2} \mathrm{~s}^{-1}$, the CCI of mizuna increased from $\sim 7$ to $\sim 40$, while that of lettuce increased from $\sim 2$ to about $\sim 10$ (Figure 4A).

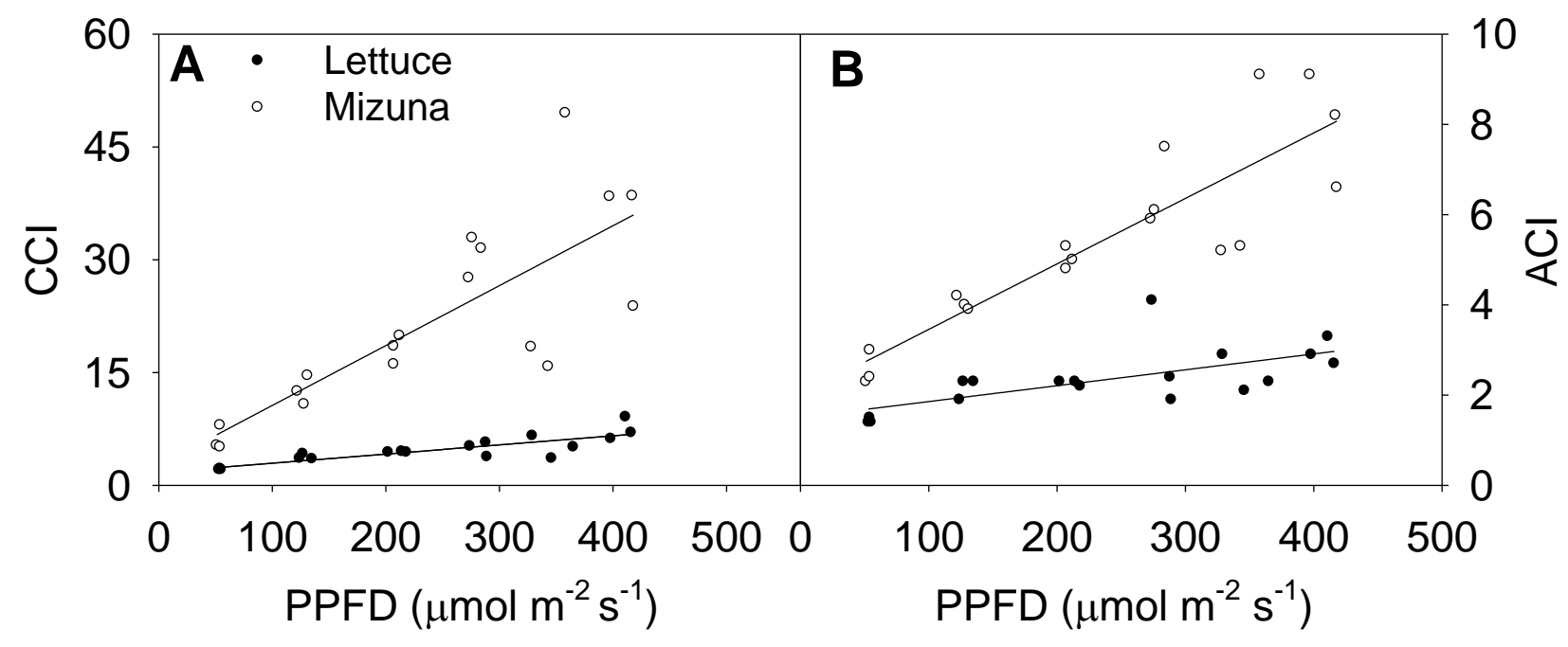

Figure 4. (A) Chlorophyll content index (CCI) and (B) anthocyanin content index (ACI) of mizuna (Brassica rapa var. japonica) and lettuce (Lactuca sativa 'Green Salad Bowl') plants grown at six different photosynthetic photon flux densities (PPFD). Data were collected a day before the harvesting (26 and 27 days for mizuna and lettuce, respectively). Lines show the results from multiple regression analysis, which indicated a significant species $\times$ PPFD interaction for both CCI $\left(R^{2}=0.82\right.$, interaction $p<0.0001)$ and $\mathrm{ACI}\left(R^{2}=0.88\right.$, interaction $\left.p<0.0001\right)$.

The ACI showed a similar pattern as CCI; increasing PPFD increased ACI in both crops $(p \leq 0.003$ ) (Figure 4B). Mizuna had a higher ACI than lettuce at all PPFD levels $(p<0.0001)$ and mizuna ACI increased more rapidly with increasing PPFD than that of lettuce. For each $1 \mu \mathrm{mol} \mathrm{m} \mathrm{m}^{-2} \mathrm{~s}^{-1}$ increase in PPFD, the ACI of mizuna increased by 0.015 and that of lettuce by 0.004 . As the PPFD increased from 50 to $400 \mu \mathrm{mol} \mathrm{m}^{-2} \mathrm{~s}^{-1}$, the ACI of mizuna increased from $\sim 3$ to $\sim 8$, while that of lettuce only increased from $\sim 2$ to about $\sim 3$.

\subsection{Quantum Yield of Photosystem II and $\mathrm{CO}_{2}$ Assimilation}

The quantum yield of photosystem II ( $\left.\Phi_{\mathrm{PSII}}\right)$ of both crops decreased linearly with increasing PPFD ( $p=0.0008$ ) (Figure 5A). Increasing PPFD by $1 \mu \mathrm{mol} \mathrm{m}^{-2} \mathrm{~s}^{-1}$ reduced $\Phi_{\text {PSII }}$ of lettuce and mizuna by $0.0003 \mathrm{~mol} \mathrm{~mol}^{-1}$. Mizuna always had a higher $\Phi_{\mathrm{PSII}}\left(\sim 0.05 \mathrm{~mol} \mathrm{~mol}^{-1}\right)$ than lettuce regardless of PPFD $(p<0.0001)$. The net $\mathrm{CO}_{2}$ assimilation rate of both crops increased with increasing PPFD, but this tended to be more pronounced in mizuna than in lettuce $(p=0.08)$. Both crops had a $\mathrm{CO}_{2}$ assimilation rate of $\sim 1 \mu \mathrm{mol} \mathrm{m} \mathrm{m}^{-2} \mathrm{~s}^{-1}$ at a PPD of $50 \mu \mathrm{mol} \mathrm{m}{ }^{-2} \mathrm{~s}^{-1}$, but at PPFD of $425 \mu \mathrm{mol} \mathrm{m}^{-2} \mathrm{~s}^{-1}$ mizuna had a $\mathrm{CO}_{2}$ assimilation rate of $\sim 18 \mu \mathrm{mol} \mathrm{m}{ }^{-2} \mathrm{~s}^{-1}$ while that of lettuce was only $\sim 13 \mu \mathrm{mol} \mathrm{m}{ }^{-2} \mathrm{~s}^{-1}$. The assimilation rate of mizuna and lettuce increased by 0.044 and $0.035 \mu \mathrm{mol} \mathrm{m}{ }^{-2} \mathrm{~s}^{-1}$ per $1 \mu \mathrm{mol} \mathrm{m}{ }^{-2} \mathrm{~s}^{-1}$ increase in PPFD, respectively. 


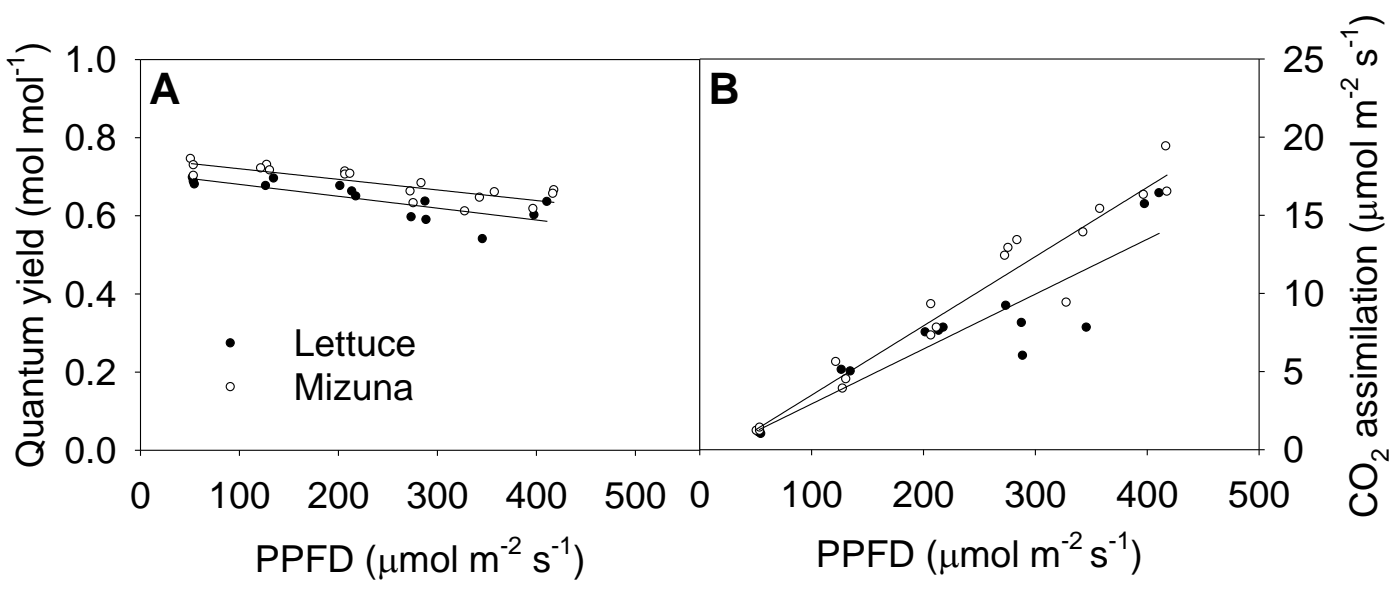

Figure 5. (A) Quantum yield of photosystem II and (B) net $\mathrm{CO}_{2}$ assimilation rate of mizuna (Brassica rapa var. japonica) and lettuce (Lactuca sativa 'Green Salad Bowl') plants grown and measured at six photosynthetic photon flux densities (PPFDs). Data were collected a day before the harvesting ( 26 and 27 days for mizuna and lettuce, respectively). Lines show the results from multiple regression analysis, which indicated no significant species $\times$ PPFD interaction for quantum yield $\left(R^{2}=0.72\right.$, interaction $p=0.62$ ), but significant effects of PPFD and species (both $p<0.0001$ ). For $\mathrm{CO}_{2}$ assimilation rate, there was a weak species $\times$ PPFD interaction effect $\left(R^{2}=0.91\right.$, interaction $\left.p=0.08\right)$.

\subsection{Final Leaf Area and Canopy Overlap Ratio}

The final leaf area of both mizuna and lettuce increased asymptotically with increasing PPFD ( $p<0.0001$ ) (Figure 6A). Both crops had the highest leaf area at PPFDs $\geq 275 \mu \mathrm{mol}$ $\mathrm{m}^{-2} \mathrm{~s}^{-1}$, but lettuce leaf area increased faster with increasing PPFD than mizuna leaf area $(p<0.0001)$. At a PPFD of $\geq 275 \mu \mathrm{mol} \mathrm{m} \mathrm{m}^{-2} \mathrm{~s}^{-1}$ lettuce had a leaf area of $\sim 1200 \mathrm{~cm}^{2}$ per plant, while that of mizuna was only $\sim 800 \mathrm{~cm}^{2}$. However, lettuce had a lower PCS at harvest compared to mizuna at PPFDs $\geq 200 \mu \mathrm{mol} \mathrm{m}^{-2} \mathrm{~s}^{-1}$ (Figure 2). This apparent contradiction between a greater leaf area and a lower PCS of lettuce can be explained by the canopy overlap ratio (leaf area/PCS); lettuce had a much higher canopy overlap ratio than mizuna at PPFDs $\geq 125 \mu \mathrm{mol} \mathrm{m} \mathrm{m}^{-2} \mathrm{~s}^{-1}$ (Figure 6B). The canopy overlap ratio of lettuce increased more rapidly, from 1.2 to 5.2 with increasing PPFD compared to that of mizuna (increasing from 1.1 to 2.3) $(p<0.0001)$.

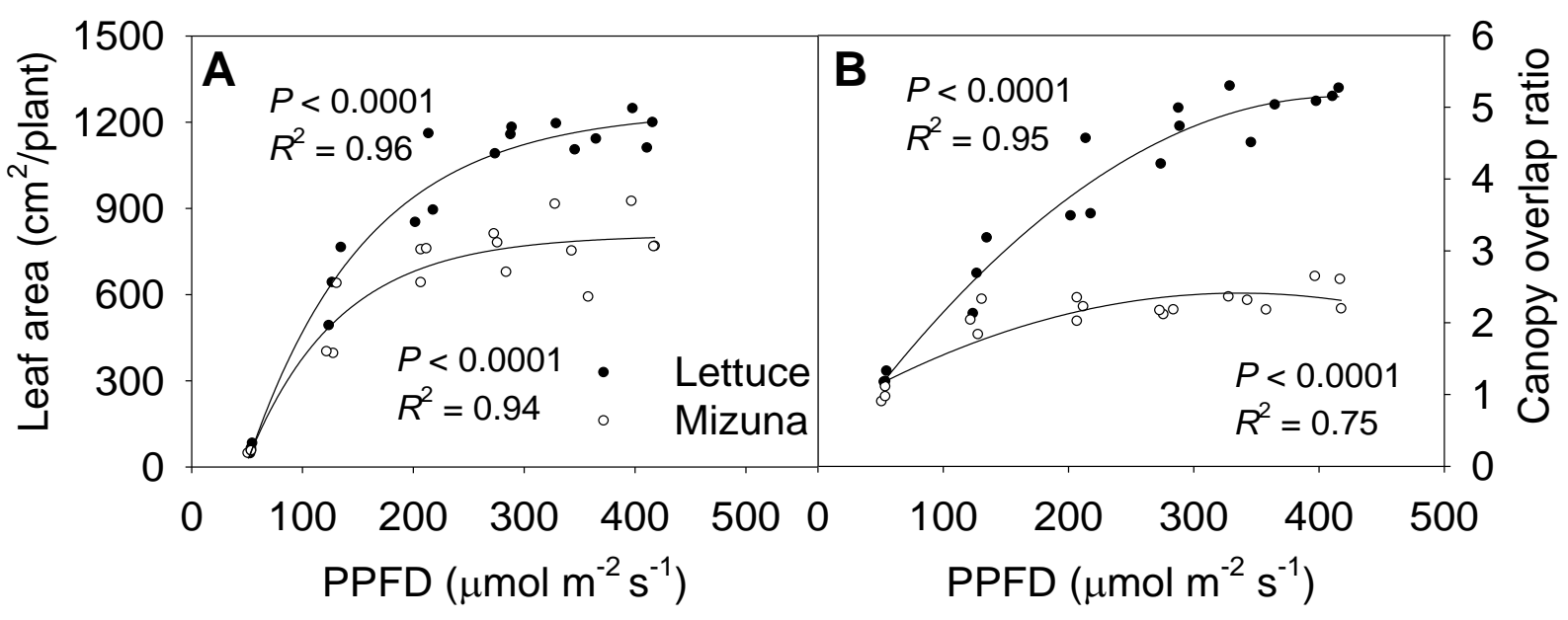

Figure 6. (A) Leaf area per plant and (B) canopy overlap ratio of mizuna (Brassica rapa var. japonica) and lettuce (Lactuca sativa 'Green Salad Bowl') plants grown at six different photosynthetic photon flux densities (PPFDs) for 27 and 28 days, respectively. The canopy overlap ratio is the ratio between the leaf area and the projected canopy size at harvest. Each data point represents the mean of nine plants. 


\subsection{Shoot Dry Weight and Specific Leaf Area}

The shoot dry weight at $425 \mu \mathrm{mol} \mathrm{m}{ }^{-2} \mathrm{~s}^{-1}$ was $\sim 50$ times higher than at $50 \mu \mathrm{mol} \mathrm{m}^{-2} \mathrm{~s}^{-1}$ for both lettuce and mizuna, although PPFD increased only $\sim 9 \times$ (Figure 7A, Figure S4). Lettuce and mizuna had a dry weight of 0.08 and $0.11 \mathrm{~g} /$ plant at a PPFD of $50 \mu \mathrm{mol} \mathrm{m}{ }^{-2} \mathrm{~s}^{-1}$ and 3.85 and $6.02 \mathrm{~g} /$ plant at a PPFD of $425 \mu \mathrm{mol} \mathrm{m}^{-2} \mathrm{~s}^{-1}$, respectively. A $1 \mu \mathrm{mol} \mathrm{m}{ }^{-2} \mathrm{~s}^{-1}$ increase in PPFD increased the dry weight of lettuce by $10.0 \mathrm{mg} /$ plant and that of mizuna by $15.8 \mathrm{mg} /$ plant. With increasing PPFD, the specific leaf area (SLA, leaf area per gram of dry weight) of both crops decreased $(p<0.0001)$ (Figure 7B). However, due to the higher leaf area and lower dry weight of lettuce compared to mizuna, the SLA of lettuce was greater than that of mizuna at all PPFDs. The difference in SLA between the two species decreased with increasing PPFD (Figure 7B).

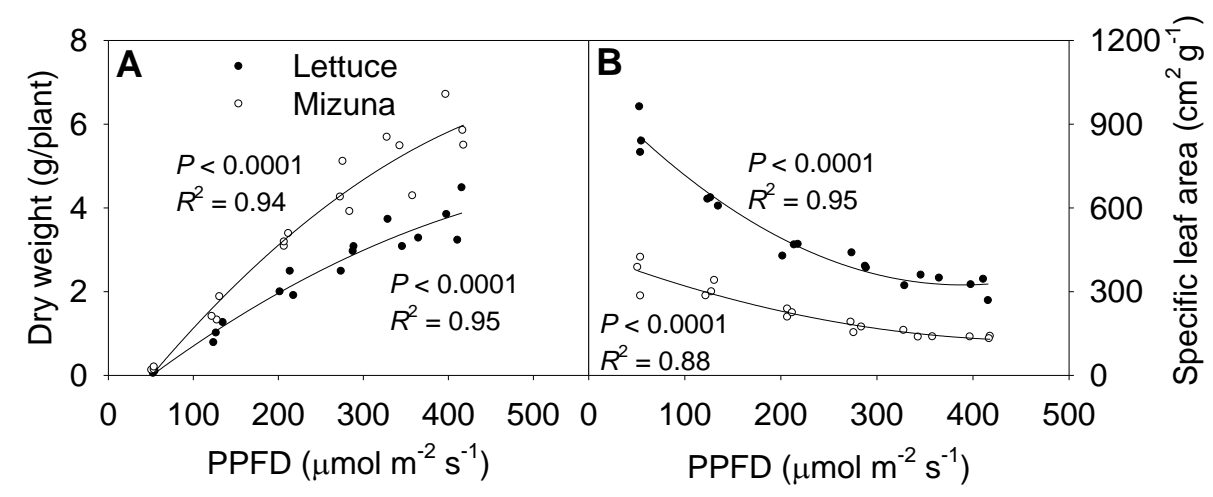

Figure 7. (A) Shoot dry weight and (B) specific leaf area of mizuna (Brassica rapa var. japonica) and lettuce (Lactuca sativa 'Green Salad Bowl') plants grown at six different photosynthetic photon flux densities (PPFDs) for 27 and 28 days, respectively. Specific leaf area is the ratio between leaf area and dry weight. Each data point represents the mean of nine plants.

\subsection{Light Use Efficiency}

Mizuna had a higher LUE than lettuce $(p<0.0001)$ (Figure 8). The LUE of mizuna was $\sim 1.1 \mathrm{~g} \mathrm{~mol}^{-1}$ at PPFDs up to $200 \mu \mathrm{mol} \mathrm{m}^{-2} \mathrm{~s}^{-1}$ and decreased to $\sim 0.75 \mathrm{~g} \mathrm{~mol}^{-1}$ at a PPFD of $425 \mu \mathrm{mol} \mathrm{m}{ }^{-2} \mathrm{~s}^{-1}$. In contrast, lettuce LUE was greatest at PPFDs of 125 to $350 \mu \mathrm{mol} \mathrm{m}^{-2} \mathrm{~s}^{-1}$ $\left(\sim 0.8 \mathrm{~g} \mathrm{~mol}^{-1}\right)$ and $\sim 0.6 \mathrm{~g} \mathrm{~mol}^{-1}$ at PPFDs of 50 and $425 \mu \mathrm{mol} \mathrm{m}^{-2} \mathrm{~s}^{-1}$.

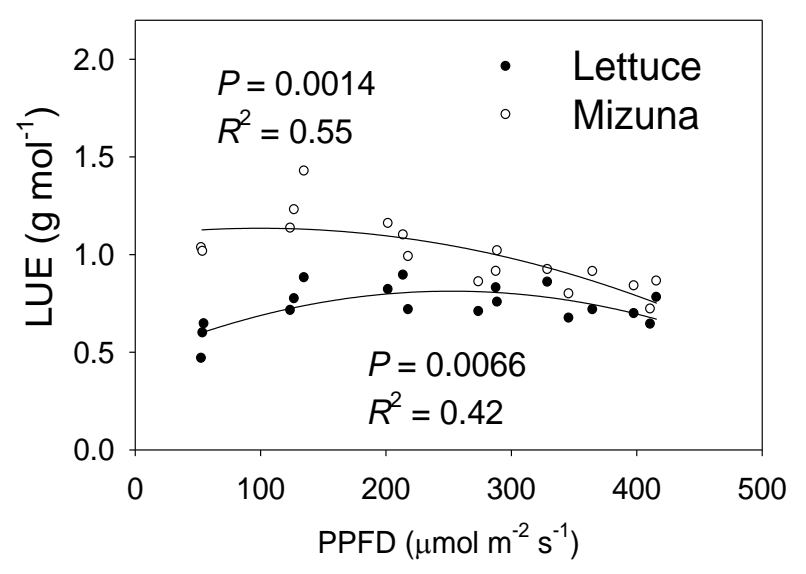

Figure 8. Light use efficiency (LUE, grams of shoot dry weight per mol of incident light) of mizuna (Brassica rapa var. japonica) and lettuce (Lactuca sativa 'Green Salad Bowl') plants grown at six different photosynthetic photon flux densities (PPFDs) for 27 and 28 days, respectively. Each data point represents the mean of nine plants. 


\section{Discussion}

Mizuna grew faster than lettuce at PPFDs $\geq 125 \mu \mathrm{mol} \mathrm{m}^{-2} \mathrm{~s}^{-1}$ (Figure 7A). A previous study conducted to identify the effects of photoperiod on leafy greens found much faster growth of mizuna compared to lettuce [18]. The difference in biomass between the two crops increased with increasing PPFD (and shorter photoperiods). The goal of the current study was to determine the underlying reasons for the growth differences between these two crops.

\subsection{Projected Canopy Size and Incident Light}

Mizuna had a larger PCS than lettuce, starting from the early growth stages (Figure 1; Figure S1). One reason for this early difference in PCS is the faster germination and larger cotyledons of mizuna compared to lettuce. Due to their small canopy size, seedlings capture only a small fraction of the provided light. Therefore, increased PCS at early stages can increase light capture and growth of seedlings [11]. A previous study compared different lettuce cultivars and found that early PCS was a good predictor of final shoot biomass [10]. We observed the same pattern in our study, with a strong positive correlation ( $R=0.91$ for lettuce and $R=0.89$ for mizuna, $p<0.0001$ ) between early PCS (lettuce $10 \mathrm{~d}$ and mizuna $8 \mathrm{~d}$ after seeding) and the dry weight of both lettuce and mizuna (Figure S2).

This higher PCS of mizuna during the early part of the growing cycle (at PPFDs $\geq 125 \mu \mathrm{mol} \mathrm{m}{ }^{-2} \mathrm{~s}^{-1}$ ) may have helped it to capture more light and grow faster than lettuce. A previous greenhouse study conducted with 'Little Gem' lettuce observed the same trend; plants with larger PCS in early growth stages absorbed more light, grew faster, and produced additional canopy faster than plants with a smaller PCS [4]. In that prior study, plants were grown with different photoperiods, but the same DLI. In contrast, plants in the current study were grown with the same photoperiod, but different PPFDs, thus resulting in different DLIs.

At a PPFD of $50 \mu \mathrm{mol} \mathrm{m}{ }^{-2} \mathrm{~s}^{-1}$, both mizuna and lettuce grew slowly and had a low PCS at harvest compared to plants grown at higher PPFDs (Figure 2). At PPFDs $\geq$ $125 \mu \mathrm{mol} \mathrm{m}{ }^{-2} \mathrm{~s}^{-1}$, the PCS of both crops was much greater than at a PPFD of $50 \mu \mathrm{mol} \mathrm{m}{ }^{-2} \mathrm{~s}^{-1}$. However, at PPFD $\geq 200 \mu \mathrm{mol} \mathrm{m}^{-2} \mathrm{~s}^{-1}$, the PCS of mizuna was greater than that of lettuce (Figure 2) $(p<0.0001)$. The growth difference between the two crops is at least partly because of the observed differences in PCS and its impact on incident light. The incident light of mizuna increased more rapidly with increasing PPFD than that of lettuce, consistent with the increasing difference in dry weight between the two crops as PPFD increased (Figures 3 and 7). Other studies also mentioned a positive correlation between PCS and incident light $[5,11,19]$. Additionally, several other studies on leafy greens show a positive correlation between biomass gain and incident light integrated over the entire crop cycle $[5,20,21]$.

\subsection{Leaf Area, Specific Leaf Area, and Canopy Overlap Ratio}

Even though lettuce had a lower PCS than mizuna, its total leaf area was larger than that of mizuna at PPFDs $\geq 125 \mu \mathrm{mol} \mathrm{m}{ }^{-2} \mathrm{~s}^{-1}$ (Figure 6A). This was due to the differences in leaf arrangement and morphology between the two species. The canopy overlap ratio of lettuce was higher than that of mizuna at PPFDs $\geq 125 \mu \mathrm{mol} \mathrm{m}^{-2} \mathrm{~s}^{-1}$ (Figure 6B), resulting in more intra-canopy shading in lettuce. With increasing PPFD, the differences in leaf area and canopy overlap ratio between the two species increased.

The SLA of lettuce was greater compared to mizuna, due to a larger total leaf area and lower shoot dry weight than mizuna at PPFDs $\geq 125 \mu \mathrm{mol} \mathrm{m}^{-2} \mathrm{~s}^{-1}$ (Figure 7B).

\subsection{Chlorophyll Content Index and Anthocyanin Content Index}

We observed a higher CCI in mizuna leaves compared to lettuce at all PPFDs (Figure 4A). Leaf light absorptance is positively associated with the CCI [12]. Therefore, mizuna likely had a higher leaf light absorptance in lettuce. However, we do not have the actual light absorptance data for this study. 
With increasing PPFD, CCI increased in both species (Figure 4A). In previous studies, CCI increased with lower PPFD [4,18]. In those studies, lower PPFDs were combined with longer photoperiods to maintain the same DLI. Chlorophyll production is a light-regulated process [22]. Therefore, the CCI increase in low PPFD treatments in prior studies was associated with longer photoperiods, which increases the amount of time available for plants to produce chlorophyll [18]. In our study, photoperiod was the same in all treatments and therefore the daily light integral was higher at higher PPFDs.

In response to increasing PPFD, the CCI increase in mizuna was about four times greater than in lettuce, indicating that mizuna acclimates more strongly to different PPFDs than lettuce (Figure 4A). The greater CCI increase in mizuna may be partly the result of a lower SLA at PPFDs $\geq 125 \mu \mathrm{mol} \mathrm{m}{ }^{-2} \mathrm{~s}^{-1}$, compared to lettuce (Figure 7B). A higher SLA is associated with thinner leaves, which typically have low chlorophyll content per unit leaf area [23]. In our study, increasing PPFD decreased the SLA of both crops (Figure 7B). Such a decrease in SLA can increase the CCI, due to increased leaf thickness. We indeed observed strong negative correlations between the SLA and CCI of mizuna $(R=-0.76, p=0.0003)$ and lettuce $(R=-0.79, p=0.0001$; Figure S3), but this relationship differed greatly between the two species. Mizuna's CCI decreased much more quickly with increasing SLA than that of lettuce. At mizuna's highest SLA $\left(\sim 375 \mathrm{~cm}^{2} \mathrm{~g}^{-1}\right)$, its CCI was similar $(\sim 5)$ to the lettuce CCI at its lowest SLA $\left(\sim 325 \mathrm{~cm}^{2} \mathrm{~g}^{-1}\right)$

The anthocyanin content index (ACI) was measured to identify whether the two crops differ in anthocyanin accumulation in response to increasing PPFD. Anthocyanins in leaves have a protective role against intense light and help dissipate excess excitation energy [24,25]. The ACI of both species did indeed increase with increasing PPFD (Figure 4B). However, the ACI of both crops was much lower than those previously reported for red leaf basil (ACI of 28-81) [26] and pak choi (ACI of 35-65) [27]. Consistent with the low ACI, we did not observe any red coloration on leaves of mizuna or lettuce, with increasing PPFD.

\subsection{Quantum Yield of Photosystem II and $\mathrm{CO}_{2}$ Assimilation}

With increasing PPFD, $\Phi_{\text {PSII }}$ of both crops decreased at a similar rate (Figure $5 \mathrm{~A}$ ). At higher PPFD, a larger proportion of the PSII reaction centers are closed and more of the absorbed light energy is dissipated as heat to minimize photoinhibition $[15,28]$. This rise in heat dissipation results in a smaller fraction of the excitation energy being directed towards the PSII reaction centers, reducing $\Phi_{\text {PSII }}[17,29]$. Many previous studies have observed a decrease in $\Phi_{\text {PSII }}$, but increasing ETR, in response to increasing PPFD [15-17]. We observed the same pattern in $\Phi_{\text {PSII }}$ with increasing PPFD. We did not calculate the ETR because leaf absorptance was not measured. However, the higher CCI of mizuna suggests higher leaf absorptance compared to lettuce [12], in which case differences in electron transport rate between the two species would have been larger than the differences in $\Phi_{\text {PSII }}$. Even though we observed a reduction in $\Phi_{\text {PSII }}$ of both crops with increasing PPFD, the $\Phi_{\text {PSII }}$ of mizuna was always higher $\left(\sim 0.05 \mathrm{~mol} \mathrm{~mol}^{-1}\right)$ than that of lettuce (Figure 5A) $(p<0.0001)$. A study conducted to understand the effects of different PPFDs on the photochemistry of three species adapted to different light levels, found a higher $\Phi_{\text {PSII }}$ and higher ETR in high-light adapted species compared to the species adapted to moderate or low-light [16]. This suggests that mizuna is better adapted to high light levels than lettuce, and therefore has a higher $\Phi_{\text {PSII }}$.

With increasing PPFD, the net $\mathrm{CO}_{2}$ assimilation rate of mizuna tended to increase more rapidly than that of lettuce (Figure $5 \mathrm{~B}, p=0.08$ ). This is consistent with the higher CCI and $\Phi_{\text {PSII }}$ of mizuna. The lower SLA of mizuna suggests thicker leaves compared to lettuce. The higher CCI associated with thicker leaves can increase the light absorptance and $\mathrm{CO}_{2}$ assimilation rate per unit leaf area [23].

\subsection{Light Use Efficiency}

Mizuna had a higher maximum $\left(1.26 \mathrm{~g} \mathrm{~mol}^{-1}\right)$ LUE than lettuce $\left(0.74 \mathrm{~g} \mathrm{~mol}^{-1}\right)(p<0.0001)$ (Figure 8). Mizuna had its maximum LUE at PPFDs from 50 to $200 \mu \mathrm{mol} \mathrm{m}{ }^{-2} \mathrm{~s}^{-1}$, while 
lettuce LUE was maximal at PPFDs of 200 to $275 \mu \mathrm{mol} \mathrm{m} \mathrm{m}^{-2} \mathrm{~s}^{-1}$. This indicates that mizuna can convert incident light into biomass more efficiently than lettuce, especially at lower PPFDs. The maximum lettuce LUE we observed $\left(0.74 \mathrm{~g} \mathrm{~mol}^{-1}\right)$ is slightly higher than the LUE previously reported (0.61-0.65 $\left.\mathrm{g} \mathrm{mol}^{-1}\right)$ for 'Green Salad Bowl' lettuce [6]. Legendre and van Iersel [6] used the same method to calculate LUE, but, did not use $\mathrm{CO}_{2}$ enrichment which may have reduced leaf photosynthesis and thus LUE.

Other studies reported substantially lower LUE values $\left(<0.6 \mathrm{~g} \mathrm{~mol}^{-1}\right)$ for lettuce [23,30], but in those studies, LUE calculations were based on the amount of light provided to the growing space, rather than light reaching the canopy of the crop. Their LUE values are thus heavily dependent on the plant density of the growing spaces. Light use efficiency can also vary among cultivars [31,32]. Therefore, it is hard to compare our LUE values of lettuce with those studies. There are no prior reports for mizuna LUE.

Multiple factors contributed to the higher LUE of mizuna. The combined effects of more chlorophyll and higher $\Phi_{\text {PSII }}$ of mizuna likely resulted in higher ETR and thus more photosynthesis than in lettuce. High photosynthetic rates can increase the relative growth rate, which in turn reduces the fraction of carbohydrates allocated to maintenance respiration and increases carbon use efficiency [33]. That in turn can increase LUE.

The LUE decreased at high PPFDs for both mizuna (PPFD $\geq 200 \mu \mathrm{mol} \mathrm{m}^{-1} \mathrm{~s}^{-1}$ ) and lettuce (PPFD $\geq 350 \mu \mathrm{mol} \mathrm{m}^{-1} \mathrm{~s}^{-1}$ ) (Figure 8). This reduction of LUE at high PPFD may be due to the decrease of $\Phi_{\text {PSII }}$ with increasing PPFD (Figure 5).

\subsection{Conclusions}

The Asian leafy green mizuna (Brassica rapa var. japonica) grows faster than oakleaf lettuce (Lactuca sativa 'Green Salad Bowl') when PPFD $\geq 125 \mu \mathrm{mol} \mathrm{m}{ }^{-2} \mathrm{~s}^{-1}$. This faster growth of mizuna is the result of a higher CCI and larger PCS (at PPFDs $\geq 125 \mu \mathrm{mol} \mathrm{m}^{-2} \mathrm{~s}^{-1}$ ), allowing mizuna to capture more light, a higher $\Phi_{\mathrm{PSII}}$ and net $\mathrm{CO}_{2}$ assimilation, and a higher LUE than lettuce. This study provides a framework for determining underlying morphological and physiological reasons for growth differences among crops. Understanding the basic determinants of crop growth is important to increase crop productivity and energy efficiency in vertical farms. Canopy imaging can be used to select crops that will grow well in vertical farms. Although we looked at a multitude of morphological and physiological factors, quantifying PCS and LUE would be adequate for the selection of crops with fast growth. Perhaps most intriguingly, our results confirm that early differences in PCS (8-10 days after seeding) are a good predictor of final biomass. Therefore, it may be possible to simply use early PCS to screen crops for rapid growth in controlled environment agriculture. This would allow for rapid throughput phenotyping and greatly accelerate the selection of promising genotypes.

\section{Materials and Methods}

\subsection{Growth Chamber Setup}

The study was conducted in a $4.4 \mathrm{~m}$ wide and $4.1 \mathrm{~m}$ long walk-in growth chamber. Cooling was provided using a top-mount refrigeration system and a dehumidifier maintained the relative humidity inside the growth chamber. The $\mathrm{CO}_{2}$ level inside the growth chamber was measured and maintained by triggering a solenoid valve to open and release $\mathrm{CO}_{2}$ from a compressed gas cylinder for 1-second intervals, whenever the $\mathrm{CO}_{2}$ concentration dropped below $800 \mu \mathrm{mol} \mathrm{mol}^{-1}$, using a $\mathrm{CO}_{2}$ transmitter (GMC20; Vaisala, Helsinki, Finland) and a datalogger (CR6, Campbell Scientific, Logan, UT, USA). Temperature and relative humidity measurements were collected every ten seconds with a probe (HMP50; Vaisala) connected to the datalogger. Using those temperature and relative humidity values, vapor pressure deficit (VPD) was calculated. Average temperature, $\mathrm{CO}_{2}$ level, and VPD inside the growth chamber were $24.2 \pm 0.2{ }^{\circ} \mathrm{C}, 825 \pm 38 \mu \mathrm{mol} \mathrm{mol}{ }^{-1}$, and $1.4 \pm 0.12 \mathrm{kPa}$ (mean $\pm \mathrm{SD}$ ), respectively.

The growth chamber contained three $2.4 \mathrm{~m}$ long $\times 0.6 \mathrm{~m}$ wide $\times 2.2 \mathrm{~m}$ high metal shelving racks with $0.9 \mathrm{~m}$ distance between the racks. Each rack had three shelves with 
a $0.6 \mathrm{~m} \times 2.4 \mathrm{~m}$ ebb-and-flow tray on each shelf. Each tray had an individual irrigation tube connected to a submersible pump. Those pumps were submerged in a fertigation tank located under the bottom shelf of each of the three metal racks. Three pumps were submerged in each fertigation tank. Each ebb-and-flow tray was divided into two $1.2 \mathrm{~m}$ long sections. Therefore, each rack had six $1.2 \mathrm{~m}$ long $\times 0.6 \mathrm{~m}$ wide $\times 0.6 \mathrm{~m}$ high sections, for a total of 18 growing sections. Each growing section had two $1.1 \mathrm{~m}$-long white LED lights (RAY series with Physiospec indoor spectrum; Fluence Bioengineering, Austin, TX, USA) hanging $0.4 \mathrm{~m}$ above the bottom of the ebb \& flow tray. Air circulation was provided by four $4 \times 4 \mathrm{~cm}^{2}$ fans in each growing section.

\subsection{Seeding and Plant Management}

We placed two groups of nine $10-\mathrm{cm}$ square pots in each growing section. Those pots were filled with a soilless substrate [80\% peat: $20 \%$ perlite (v/v) (Fafard 1P; SunGro Horticulture, Agawam, MA, USA)]. Nine pots were seeded with mizuna (Brassica rapa var. japonica) and nine pots with lettuce (Lactuca sativa 'Green Salad Bowl'). To prevent algae growth on the surface of the substrate, the top $1 \mathrm{~cm}$ of each pot was filled with calcined clay (Turface ${ }^{\circledR}$ Pro League Elite, Profile Products LLC, Buffalo Grove, IL). Plants were sub-irrigated daily for 5 minutes with a nutrient solution containing $100 \mathrm{mg} \mathrm{L}^{-1} \mathrm{~N}$ made with a water-soluble fertilizer (15N-2.2P-12.45K, Peters Excel 15-5-15 Cal-Mag Special; Everris NA Inc, Dublin, OH, USA). Algaecide (ZeroTol 2.0, BioSafe Systems LLC, East Hartford, CT, USA) was applied to the surface of the substrate twice during the study, at a ratio of 1:400 (ZeroTol: water) as an algae preventative. Plants were grown under six treatments with different photosynthetic photon flux densities (PPFD) $(\sim 50,125,200$, 275,350 , and $425 \mu \mathrm{mol} \mathrm{m} \mathrm{m}^{-2} \mathrm{~s}^{-1}$ at the center of each section) (Table 1 ). Treatments were randomly allocated to one of the six sections of each metal rack. The PPFD was controlled by sending a pulse width modulation signal from the datalogger to the dimmable drivers powering the light fixtures. The LED lights were on for 16 hours per day. Therefore, plants received daily light integrals of $\sim 3.1,7.4,12.1,16.2,19.9$, and $23.6 \mathrm{~mol} \mathrm{~m}^{-2} \mathrm{~d}^{-1}$ at the center of each section in the six treatments (Table 1 ).

Table 1. Photosynthetic photon flux densities (PPFD), and the average daily light integral (DLI) at the center of the tray of each treatment. The photoperiod was 16 hours for all the treatments. Values show the mean \pm standard deviation.

\begin{tabular}{|c|c|}
\hline 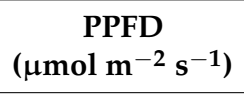 & $\begin{array}{c}\text { DLI } \\
\left(\mathrm{mol} \mathrm{m}^{-2} \mathrm{~d}^{-1}\right)\end{array}$ \\
\hline $53 \pm 2$ & $3.1 \pm 0.1$ \\
\hline $128 \pm 6$ & $7.4 \pm 0.3$ \\
\hline $210 \pm 9$ & $12.1 \pm 0.5$ \\
\hline $281 \pm 14$ & $16.2 \pm 0.8$ \\
\hline $345 \pm 15$ & $19.9 \pm 0.8$ \\
\hline $410 \pm 16$ & $23.6 \pm 1.0$ \\
\hline
\end{tabular}

\subsection{Data Collection and Calculations}

Mizuna and lettuce canopy images were captured twice a week throughout the growing period, using a chlorophyll fluorescence imaging setup. For the fluorescence imaging, we used a monochrome camera (CM3-U3-31S4M-CS, Chameleon3 USB3 camera, FLIR Systems, Inc., Arlington, VA, USA) with a 665 nm longpass filter (LP665 Dark Red Longpass Filter; Midopt Midwest Optical Systems, Inc., Palatine, IL, USA) attached to the lens. The camera was mounted facing downward inside of a $1.2 \mathrm{~m} \times 0.6 \mathrm{~m} \times 1.5 \mathrm{~m}$ grow tent. A blue LED panel was mounted inside the tent next to the camera to excite chlorophyll and induce fluorescence. Reemitted light from chlorophyll fluorescence was captured by the camera. Canopy images were taken biweekly on groups of nine plants. Those images were then analyzed with ImageJ software (ImageJ 1.52a, National Institute of Health, Bethesda, MD, USA) to determine the PCS. These PCS data were divided by nine to 
determine the PCS per plant. Those values were plotted against time and sigmoidal curves $[\mathrm{f}=\mathrm{a} /(1+\exp (-(\mathrm{x}-\mathrm{x} 0) / \mathrm{b}))]$ were fitted (SigmaPlot 11.0, Systat software, Inc., San Jose, CA, USA). This was done for all individual treatments and replicates $\left(R^{2} \geq 0.99\right)$. Using the coefficients for the sigmoidal equation, the daily PCS was estimated (Microsoft Excel 365, Microsoft Corporation, Redmond, WA, USA). The daily PCS data were multiplied by the DLI received in each corresponding treatment to calculate the daily incident light per plant. By adding those daily incident light values, the total incident light on the canopy throughout the growing period was calculated.

One day before the harvest, leaf CCI and leaf anthocyanin content index (ACI) were measured using chlorophyll and anthocyanin meters (CCM-200 plus and ACM-200 plus; Apogee Instruments, Logan, UT, USA) on uppermost fully-expanded leaves. Then, the quantum yield of photosystem II ( $\left.\Phi_{\mathrm{PSII}}\right)$ and $\mathrm{CO}_{2}$ assimilation were measured using a leaf gas exchange system, equipped with a chlorophyll fluorometer (CIRAS-3 Portable Photosynthesis System: PP Systems, Amesbury, MA, USA). The corresponding PPFD level of each treatment was provided using the white LED light in the leaf cuvette during the measurements. The average leaf temperature, vapor pressure deficit, and $\mathrm{CO}_{2}$ concentration inside the cuvette were $24.5^{\circ} \mathrm{C}, 1.3 \mathrm{kPa}$, and $781 \mu \mathrm{mol} \mathrm{mol}^{-1}$, respectively, to mimic the conditions inside the growth chamber at the time of the data collection.

At the end of the study, lettuce plants were harvested at 28 days after seeding and mizuna plants were harvested at 27 days after seeding. The total leaf area of each group of plants was measured using a leaf area meter (LI-3100 leaf area meter; LI-COR Biosciences, Lincoln, NE, USA). After drying them at $80^{\circ} \mathrm{C}$ for 7 days, shoot dry weight of each group of plants was also measured. Both leaf area and shoot dry weight value were divided by nine to calculate the per plant leaf area and shoot dry weight. By dividing the leaf area by the associated PCS at harvest, the canopy overlap ratio was calculated. Specific leaf area (SLA) was calculated by dividing the leaf area of a plant by the shoot dry weight. To calculate LUE, shoot dry weight was divided by the total incident light that the plant received over the growing period.

\subsection{Experimental Design and Statistical Analysis}

The experiment design was a randomized complete block with a split-plot with one metal shelving rack as a block, 3 blocks, six PPFD levels as the main treatment, and the two crops as the split plot. The experimental unit was a group of nine plants. Regression analyses (linear, quadratic, sigmoidal, and exponential rise to maximum) were conducted with time or average PPFD of each treatment as the independent variable (SigmaPlot 11.0, Systat software, Inc., San Jose, CA, USA). Finally, multiple regression analysis $(\alpha<0.05)$ was performed using SAS (SAS University edition; SAS Institute, Cary, NC, USA) with PPFD as a continuous and species as a class variable to test for PPFD and species effects on PCS, incident light over the growing period, CCI, ACI, $\Phi_{\mathrm{PSII}}, \mathrm{CO}_{2}$ assimilation, leaf area, canopy overlap ratio, dry weight, SLA, and LUE. When there was no significant interaction between species and PPFD, the interaction term was removed from the model and the main effects of species and PPFD were used to describe the treatment effects.

Supplementary Materials: The following supplementary figures are available online at https: / / www.mdpi.com/article/10.3390/plants10040704/s1, Figure S1. The projected canopy images captured during the growing period of mizuna (Brassica rapa var. japonica) (A-D) and lettuce (Lactuca sativa 'Green Salad Bowl') (E-H) grown at $425 \mu \mathrm{mol} \mathrm{m}{ }^{-2} \mathrm{~s}^{-1}$. The first three images of mizuna (A-C) and lettuce (E-G) were captured at $5(\mathrm{~A}, \mathrm{E}), 15(\mathrm{~B}, \mathrm{~F})$, and 19 days $(\mathrm{C}, \mathrm{G})$ after seeding. The last images of mizuna $(\mathrm{D})$ and lettuce $(\mathrm{H})$ were captured during the harvest $(27$ and 28 days, respectively); Figure S2. Correlation between early projected canopy size (lettuce at 10 days and mizuna at 8 days, after seeding) and final shoot dry weight of lettuce (Lactuca sativa 'Green Salad Bowl') and mizuna (Brassica rapa var. japonica); Figure S3. Correlation between specific leaf area (leaf area/shoot dry weight) and chlorophyll content index (CCI) of lettuce (Lactuca sativa 'Green Salad Bowl') and mizuna (Brassica rapa var. japonica); Figure S4. The appearance of lettuce (Lactuca sativa 'Green Salad Bowl', top) and mizuna (Brassica rapa var. japonica, bottom) at the end of the growing 
cycle for plants grown at six different photosynthetic photon flux densities (upper left corner of each picture).

Author Contributions: Conceptualization, T.C.J., and M.W.v.I.; methodology, T.C.J. and M.W.v.I.; formal analysis, T.C.J. and M.W.v.I.; investigation, T.C.J. and M.W.v.I.; data curation, T.C.J.; writingoriginal draft preparation, T.C.J.; writing-review and editing, T.C.J. and M.W.v.I.; visualization, T.C.J.; supervision, M.W.v.I.; funding acquisition, M.W.v.I. Both authors have read and agreed to the published version of the manuscript.

Funding: This research was funded by the U.S. Department of Agriculture-National Institute of Food and Agriculture-Specialty Crop Research Initiative Award No. 2018-51181-28365 (Project "Lighting Approaches to Maximize Profits". www.hortlamp.org).

Institutional Review Board Statement: Not applicable.

Informed Consent Statement: Not applicable.

Data Availability Statement: Data used in this study is available at https:/ / drive.google.com/ drive/folders/1BgP771XRRsbZHCttrHB-SueqV4nU0JMf.

Acknowledgments: We thank Eleanor Jane Rager for her assistance with data collection and Fluence Bioengineering for donating the light fixtures.

Conflicts of Interest: The authors declare no conflict of interest. The funders had no role in the design of the study; in the collection, analyses, or interpretation of data; in the writing of the manuscript, or in the decision to publish the results.

\section{References}

1. Birkby, J. Vertical farming. In ATTRA Sustainable Agriculture; National Center for Appropriate Technology: Butte, MT, USA, 2016; pp. 1-12.

2. Stober, K.; Lee, K.; Yamada, M.; Pattison, M. Energy Savings Potential of SSL in Horticultural Applications; Office of Energy Efficiency and Renewable Energy, U.S. Dept. of Energy: Washington, DC, USA, 2017.

3. Banerjee, C.; Adenaeuer, L. Up, up and away! The economics of vertical farming. J. Agric. Stud. 2014, 2, 40-60. [CrossRef]

4. Weaver, G.; van Iersel, M.W. Longer Photoperiods with Adaptive Lighting Control Can Improve Growth of Greenhouse-grown 'Little Gem' Lettuce (Lactuca sativa). HortScience 2020, 55, 573-580. [CrossRef]

5. Klassen, S.P.; Ritchie, G.L.; Frantz, J.M.; Pinnock, D.R.; Bugbee, B. Real-Time Imaging of Ground Cover: Relationships with Radiation Capture, Canopy Photosynthesis, and Daily Growth Rate. In Digital Imaging and Spectral Techniques: Applications to Precision Agriculture and Crop Physiology; American Society of Agronomy: Minneapolis, MN, USA, 2003; pp. 3-14.

6. Legendre, R.; van Iersel, M.W. Supplemental Far-Red Light Stimulates Lettuce Growth: Disentangling Morphological and Physiological Effects. Plants 2021, 10, 166. [CrossRef] [PubMed]

7. Campillo, C.; Prieto, M.H.; Daza, C.; Moñino, M.J.; García, M.I. Using Digital Images to Characterize Canopy Coverage and Light Interception in a Processing Tomato Crop. HortScience 2008, 43, 1780. [CrossRef]

8. Purcell, L. Soybean Canopy Coverage and Light Interception Measurements Using Digital Imagery. Crop Sci. 2000, 40, 834-837. [CrossRef]

9. Cometti, N.N.; Frantz, J.; Bugbee, B. Imaging Lettuce Growth: A Comparison between \% Ground Coverage and \% PPF Absorption by Lettuce Grown in Hydroponics; Crop Physiology Laboratory, USU: Logan, UT, USA, 2003.

10. Kim, C.; van Iersel, M.W. Morphological and physiological screening for growth differences among 11 lettuce cultivars. In Proceedings of the ASHS 2019 Annual Conference, Las Vegas, NV, USA, 21-25 July 2019; pp. S89-S90.

11. Elkins, C.; van Iersel, M.W. Longer Photoperiods with the Same Daily Light Integral Improve Growth of Rudbeckia Seedlings in a Greenhouse. HortScience 2020, 55, 1676-1682. [CrossRef]

12. Bauerle, W.L.; Weston, D.J.; Bowden, J.D.; Dudley, J.B.; Toler, J.E. Leaf absorptance of photosynthetically active radiation in relation to chlorophyll meter estimates among woody plant species. Sci. Hortic. 2004, 101, 169-178. [CrossRef]

13. Baker, N.R. Chlorophyll fluorescence: A probe of photosynthesis in vivo. Annu. Rev. Plant Biol. 2008, 59, 89-113. [CrossRef]

14. Maxwell, K.; Johnson, G.N. Chlorophyll fluorescence-A practical guide. J. Exp. Bot. 2000, 51, 659-668. [CrossRef]

15. Weaver, G.; van Iersel, M.W. Photochemical Characterization of Greenhouse-grown Lettuce (Lactuca sativa L. 'Green Towers') with Applications for Supplemental Lighting Control. HortScience 2019, 54, 317-322. [CrossRef]

16. Zhen, S.; van Iersel, M.W. Photochemical Acclimation of Three Contrasting Species to Different Light Levels: Implications for Optimizing Supplemental Lighting. J. Am. Soc. Hortic. Sci. 2017, 142, 346-354. [CrossRef]

17. Demmig-Adams, B.; Cohu, C.M.; Muller, O.; Adams, W.W. Modulation of photosynthetic energy conversion efficiency in nature: From seconds to seasons. Photosynth Res. 2012, 113, 75-88. [CrossRef]

18. Palmer, S.; van Iersel, M.W. Increasing Growth of Lettuce and Mizuna under Sole-Source LED Lighting Using Longer Photoperiods with the Same Daily Light Integral. Agronomy 2020, 10, 1659. [CrossRef] 
19. Bhuiyan, R.; van Iersel, M.W. Only Extreme Fluctuations in Light Levels Reduce Lettuce Growth Under Sole Source Lighting. Front. Plant Sci. 2021, 12, 24. [CrossRef]

20. Tei, F.; Scaife, A.; Aikman, D.P. Growth of Lettuce, Onion, and Red Beet. 1. Growth Analysis, Light Interception, and Radiation Use Efficiency. Ann. Bot. 1996, 78, 633-643. [CrossRef]

21. Wurr, D.C.E.; Fellows, J.R. The influence of solar-radiation and temperature on the head weight of crisp lettuce. J. Hortic. Sci. 2015, 66, 183-190. [CrossRef]

22. Reinbothe, S.; Reinbothe, C. The regulation of enzymes involved in chlorophyll biosynthesis. Eur. J. Biochem. 1996, 237, 323-343. [CrossRef]

23. Zou, J.; Zhang, Y.; Zhang, Y.; Bian, Z.; Fanourakis, D.; Yang, Q.; Li, T. Morphological and physiological properties of indoor cultivated lettuce in response to additional far-red light. Sci. Hortic. 2019, 257, 108725. [CrossRef]

24. Manetas, Y.; Drinia, A.; Petropoulou, Y. High Contents of Anthocyanins in Young Leaves are Correlated with Low Pools of Xanthophyll Cycle Components and Low Risk of Photoinhibition. Photosynthetica 2002, 40, 349-354. [CrossRef]

25. Karageorgou, P.; Manetas, Y. The importance of being red when young: Anthocyanins and the protection of young leaves of Quercus coccifera from insect herbivory and excess light. Tree Physiol. 2006, 26, 613-621. [CrossRef]

26. Ferrarezi, R.S.; Bailey, D.S. Basil Performance Evaluation in Aquaponics. HortTechnology 2019, 29, 85. [CrossRef]

27. Mickens, M.A.; Torralba, M.; Robinson, S.A.; Spencer, L.E.; Romeyn, M.W.; Massa, G.D.; Wheeler, R.M. Growth of red pak choi under red and blue, supplemented white, and artificial sunlight provided by LEDs. Sci. Hortic. 2019, 245, 200-209. [CrossRef]

28. Ruban, A.V. Quantifying the efficiency of photoprotection. Philos. Trans. R. Soc. Lond. B Biol. Sci. 2017, 372, 20160393. [CrossRef]

29. Ruban, A.V. Evolution under the sun: Optimizing light harvesting in photosynthesis. J. Exp. Bot. 2015, 66, 7-23. [CrossRef] [PubMed]

30. Nemali, K.S.; van Iersel, M.W. Acclimation of wax begonia to light intensity: Changes in photosynthesis, respiration, and chlorophyll concentration. J. Am. Soc. Hortic. Sci. 2004, 129, 745-751. [CrossRef]

31. Muurinen, S.; Peltonen-Sainio, P. Radiation-use efficiency of modern and old spring cereal cultivars and its response to nitrogen in northern growing conditions. Field Crop. Res. 2006, 96, 363-373. [CrossRef]

32. Rosenthal, W.; Gerik, T. Radiation use efficiency among cotton cultivars. Agron. J. 1991, 83, 655-658. [CrossRef]

33. Van Iersel, M. Carbon use efficiency depends on growth respiration, maintenance respiration, and relative growth rate. A case study with lettuce. Plant Cell Environ. 2003, 26, 1441-1449. [CrossRef] 